This item was submitted to Loughborough's Research Repository by the author.

Items in Figshare are protected by copyright, with all rights reserved, unless otherwise indicated.

\title{
Organocatalytic asymmetric domino Michael-Henry reaction for the synthesis of substituted bicyclo[3.2.1]octan-2-ones
}

PLEASE CITE THE PUBLISHED VERSION

http://dx.doi.org/10.1039/c3cc39165e

\section{PUBLISHER}

(c) Royal Society of Chemistry

\section{VERSION}

AM (Accepted Manuscript)

\section{PUBLISHER STATEMENT}

This work is made available according to the conditions of the Creative Commons Attribution-NonCommercialNoDerivatives 4.0 International (CC BY-NC-ND 4.0) licence. Full details of this licence are available at: https://creativecommons.org/licenses/by-nc-nd/4.0/

\section{LICENCE}

CC BY-NC-ND 4.0

\section{REPOSITORY RECORD}

Tsakos, Michail, Mark R.J. Elsegood, and Christoforos G Kokotos. 2019. "Organocatalytic Asymmetric Domino Michael-henry Reaction for the Synthesis of Substituted Bicyclo[3.2.1]octan-2-ones". figshare. https://hdl.handle.net/2134/18334. 


\title{
Organocatalytic asymmetric domino Michael-Henry reaction for the synthesis of substituted bicyclo[3.2.1]octan-2-ones
}

\author{
Michail Tsakos, ${ }^{a}$ Mark R. J. Elsegood $^{b}$ and Christoforos G. Kokotos ${ }^{* a}$ \\ Received (in $X X X, X X X)$ Xth $X X X X X X X X X 20 X X$, Accepted Xth $X X X X X X X X X 20 X X$ \\ DOI: 10.1039/b000000x
}

The first organocatalytic asymmetric reaction between 1,4 cyclohexanedione and nitroalkenes have been studied, affording bicyclo[3.2.1]octane derivatives containing four continuous stereogenic centres. The products were obtained ${ }_{10}$ through a domino Michael-Henry process as a single diastereoisomer with excellent enantioselectivities.

In recent years, domino and cascade reactions have attracted the interest of organic chemistry research, as they constitute a powerful tool for the formation of several bonds in a one-step 15 process. ${ }^{1}$ The application of these reactions in the field of organocatalysis $^{2}$ is particularly appealing because it can lead to the formation of complex structures with high stereoselectivities, in an operationally simple and straightforward manner. Amongst the numerous strategies employed in this category, ${ }^{3}$ domino 20 Michael-Henry reaction ${ }^{4}$ plays a pivotal role as these reactions constitute two of the most widely used reactions in organic asymmetric synthesis. ${ }^{5,6}$

In line with our latest studies on the asymmetric Michael addition of ketones to nitroalkenes utilizing bifunctional 25 organocatalysts, ${ }^{7}$ we became interested in the use of 1,4cyclohexanedione as the Michael donor. Rueping et al and Zhao et al reported the tandem Michael-Henry reaction of 1,2cyclohexanedione with nitroalkenes. ${ }^{8,9}$ The only example utilising a modified tricarbonyl 1,4-diketone has been reported by ${ }_{30}$ Zhong and co-workers. ${ }^{10}$ Bearing in mind these literature reports, we envisaged that 1,4-cyclohexanedione could be used for the first time in a such a reaction and could also undergo a similar reaction sequence to assemble a multifunctionalized bicyclo[3.2.1] octane structure [Eq. (1)]. This unprecedented 35 methodology would lead to a skeleton which is encountered in numerous natural products and biologically active molecules, ${ }^{11}$ and any enantioselective synthetic route to this structural motif could be of great importance.

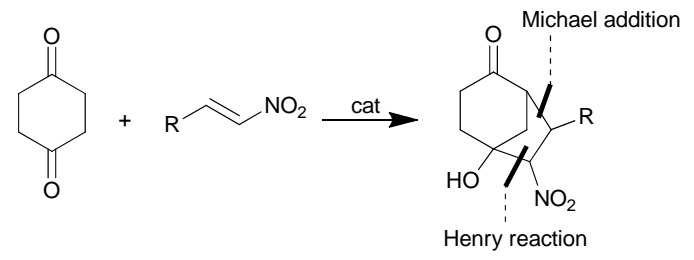

${ }_{40}$ We initiated our study by choosing as a model reaction the addition of 1,4-cyclohexanedione $\mathbf{1}$ to phenyl nitrodiene 2a in the
Table 1 Catalyst screening and optimization studies for the asymmetric domino Michael-Henry reaction. ${ }^{\alpha}$

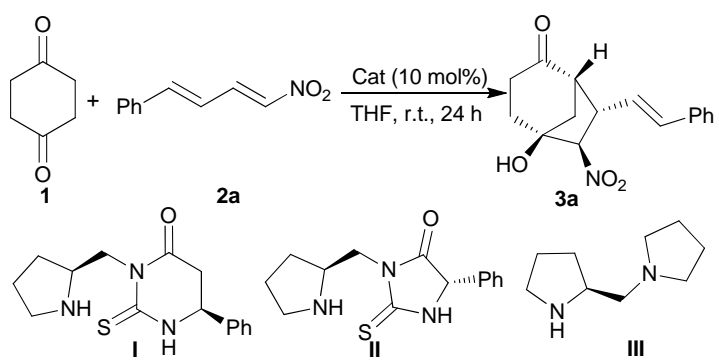

\begin{tabular}{ccccc}
\hline Entry & Catalyst & Additives $(10 \mathrm{~mol} \%)$ & ${\text { Yield }(\%)^{\mathrm{b}}}$ & $e e(\%)^{\mathrm{c}}$ \\
\hline 1 & I & 4-NBA, $\mathrm{H}_{2} \mathrm{O}^{\mathrm{d}}$ & 91 & 96 \\
2 & II & 4-NBA, $\mathrm{H}_{2} \mathrm{O}^{\mathrm{d}}$ & 22 & 90 \\
3 & III & - & 92 & 75 \\
4 & I & 4-CBA, $\mathrm{H}_{2} \mathrm{O}^{\mathrm{d}}$ & 58 & 89 \\
5 & I & $4-\mathrm{NBA}$ & Traces & - \\
$6^{\text {e }}$ & I & 4-NBA, $\mathrm{H}_{2} \mathrm{O}^{\mathrm{d}}$ & 72 & 96 \\
$7^{\mathrm{f}}$ & I & 4-NBA, $\mathrm{H}_{2} \mathrm{O}^{\mathrm{d}}$ & 75 & 96
\end{tabular}

${ }_{45}{ }^{a}$ Reactions were performed using $1(0.2 \mathrm{mmol})$ and $2 \mathrm{a}(0.1 \mathrm{mmol})$ with $10 \mathrm{~mol} \%$ of catalyst and additive in dry THF $(0.25 \mathrm{~mL})$ for 24 hours at room temperature. ${ }^{\mathrm{b}}$ Isolated yield. ${ }^{\mathrm{c}}$ The enantiomeric excess (ee) was determined by chiral HPLC. d $50 \mu \mathrm{L}$ of water were used. ${ }^{\mathrm{e}} 5 \mathrm{~mol} \%$ of catalyst I was used. ${ }^{\mathrm{f}} 0.11 \mathrm{mmol}$ (1.1 equiv) of 1 was used. 4-NBA : 450 Nitrobenzoic acid, 4-CBA : 4-Cyanobenzoic acid.

presence of L-proline as the chiral catalyst. The use of nitrodienes as the Michael acceptor is considered much more challenging ${ }^{7 d, 7 e}$ and it remains underdeveloped in comparison to the extensively 55 studied nitrostyrenes. Indeed, proline enabled the reaction forming the bicyclic compound 3a in excellent yield but in a nearly racemic form. This result led us to the assumption that the domino Michael-Henry reaction proceeds through an enamine activation mode, ${ }^{12}$ as opposed to the existing protocols ${ }^{8,10}$ that 60 suggest the formation of the enolic tautomer of the dione by a cinchona-alkaloid derived catalyst. To support our hypothesis, we repeated the reaction using catalytic amounts of tertiary amine bases that cannot form an enamine intermediate with the dione. Thus, we tested an achiral base, such as DABCO, and a ${ }_{65}$ bifunctional base, such as quinine, and in both cases no reaction took place.

Based on these observations, we set out to develop an 
asymmetric version of this domino reaction. Several bifunctional catalysts were screened, but only the proline derived catalysts IIII displayed noteworthy effects on the outcome of the reaction (Table 1, entries 1-3. See ESI $\uparrow$ for full optimization study). ${ }_{5}$ Catalysts I and II developed by us, ${ }^{7 b}$ bearing a thioxotetrahydropyrimidinone or a thiohydantoin ring respectively, delivered the product in excellent enantioselectivity, but the size of the ring exhibited a tremendous impact on the activity of the catalyst (Table 1, entry 1 vs 2). Catalyst III led to 10 high yield but the selectivity dropped significantly (Table 1, entry 3). It has to be highlighted that compound 3a was formed as a single diastereoisomer in all cases, demonstrating the excellent stereocontrol of this protocol on four continuous stereogenic centres. To optimize the reaction conditions, several solvents and 15 additives were examined in the presence of $10 \mathrm{~mol} \%$ of catalyst I (Table 1 and ESI $\dagger$ ). Polar solvents that could solubilise efficiently the dione favoured the reaction, with THF being the optimum both in terms of yield and selectivity. On the other hand, it is well documented that a careful selection of additives can play a 20 significant role in the activity of the catalyst. ${ }^{13}$ Thus, 4nitrobenzoic acid made an ideal pair with our catalyst providing the proper $\mathrm{pKa}$ value for maximum result (Table 1, entry 1 vs 4), while a controlled amount of water proved to be essential for the catalyst's turnover (Table 1 , entry 1 vs 5 ). Moreover, reducing 25 the catalyst loading to $5 \mathrm{~mol} \%$, or the ratio of dione to nitrodiene to 1.1:1 led to decreased yields, albeit the excellent enantioselectivity was maintained (Table 1, entries 6 and 7).

With optimal conditions in hand, the scope and limitations of our method was studied. An array of aromatic nitrodienes bearing 30 electron-donating or electron withdrawing substituents on the phenyl ring could be well tolerated, delivering the bicyclic products 3a-e in good to high yields and excellent enantioselectivity (Table 2, entries 2-5). Nitrodiene 2 f bearing a methyl group at the $\alpha$ - position with respect to the phenyl ring, 35 was also successfully employed (Table 2, entry 6).

To broaden the scope of our methodology, nitrodienes were replaced by aromatic nitrostyrenes as the electrophilic partner. Unfortunately, when we employed the same reaction conditions

Table 2 Domino Michael-Henry reaction between dione $\mathbf{1}$ and nitrodienes 402 utilizing catalyst $\mathbf{I}^{\alpha}$

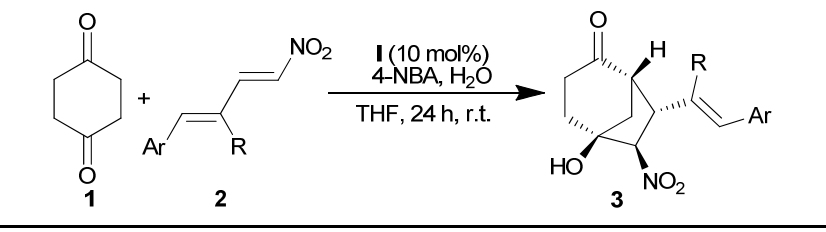

\begin{tabular}{cccc}
\hline Entry & Ar, R & Yield (\%) & $e e(\%)^{\mathrm{b}}$ \\
\hline 1 & $\mathrm{Ph}, \mathrm{H} \mathrm{(2a)}$ & 3a, 91 & 96 \\
2 & 4-OMe-Ph, H (2b) & 3b, 56 & 94 \\
3 & 4-Cl-Ph, H (2c) & 3c, 72 & 91 \\
4 & 2- $\mathrm{NO}_{2}-\mathrm{Ph}, \mathrm{H} \mathrm{(2d)}$ & $\mathbf{3 d}, 89$ & 86 \\
5 & 4- $\mathrm{NO}_{2}-\mathrm{Ph}, \mathrm{H} \mathrm{(2e)}$ & $\mathbf{3 e}, 73$ & 97 \\
6 & $\mathrm{Ph}, \mathrm{Me} \mathrm{(2f)}$ & $\mathbf{3 f}, 70$ & 95
\end{tabular}

${ }^{a}$ Reactions were performed using $1(0.2 \mathrm{mmol})$ and $2(0.1 \mathrm{mmol})$ in the presence of catalyst $\mathbf{I}(10 \mathrm{~mol} \%)$, 4-NBA $(10 \mathrm{~mol} \%)$ and $\mathrm{H}_{2} \mathrm{O}(50 \mu \mathrm{L})$ in dry THF $(0.25 \mathrm{~mL})$ at room temperature for 24 hours. $^{\mathrm{b}}$ Isolated yield. ${ }^{\mathrm{c}}$ 45 The enantiomeric excess (ee) was determined by chiral HPLC.
Table 3 Domino Michael-Henry reaction between dione $\mathbf{1}$ and nitrostyrenes $\mathbf{4}$ utilizing catalyst $\mathbf{I}^{\alpha}$

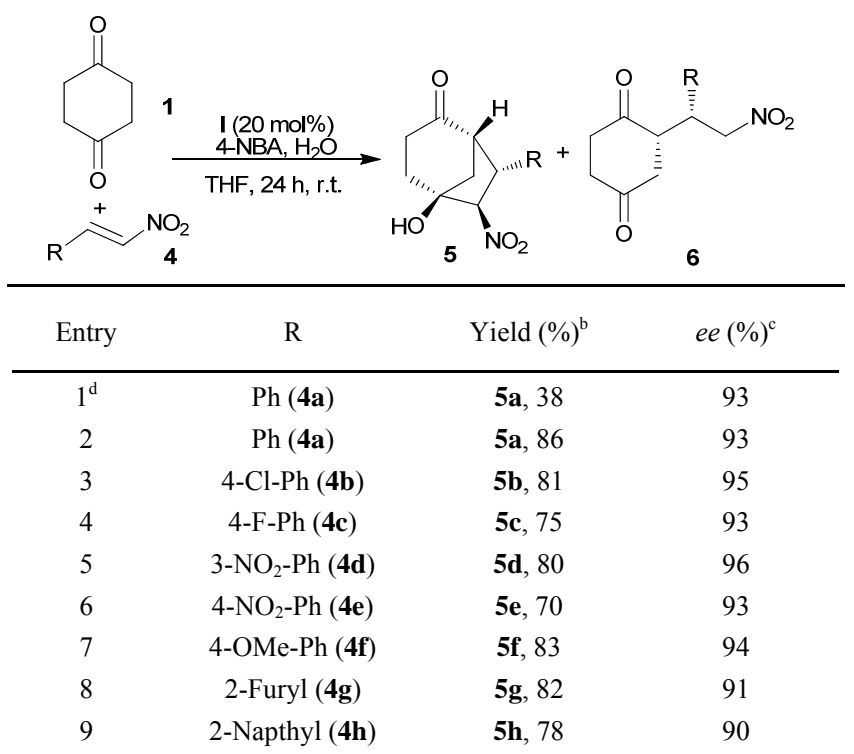

${ }^{a}$ Reactions were performed using $1(0.2 \mathrm{mmol})$ and $4(0.1 \mathrm{mmol})$ in the 50 presence of catalyst $\mathbf{I}(20 \mathrm{~mol} \%)$, 4-NBA $(20 \mathrm{~mol} \%)$ and $\mathrm{H}_{2} \mathrm{O}(50 \mu \mathrm{L})$ in dry THF $(0.25 \mathrm{~mL})$ at room temperature for 24 hours. ${ }^{\mathrm{b}}$ Isolated yield. ${ }^{\mathrm{c}}$ The enantiomeric excess (ee) was determined by chiral HPLC. ${ }^{\mathrm{d}} 10 \mathrm{~mol} \%$ of catalyst $\mathbf{I}$ and 4-NBA were used.

55 used for nitrodienes, we encountered a significant handicap with trans- $\beta$-nitrostyrene $4 a$. The reaction rate was much slower (a reaction time of 4 days was required in order to reach completion), while simultaneously the second, intramolecular ring closing, step experienced difficulties in advancing, thus 60 leading to the formation of intermediate $\mathbf{6 a}$ in $10 \%$ yield (Table 3 , entry 1). The latter was probably due to steric repulsion and/or stabilizing factors from the adjacent bulky phenyl group. To overcome this obstacle, $20 \mathrm{~mol} \%$ of catalyst $\mathbf{I}$ was used and the desired product $5 \mathbf{a}$ was delivered as a single diastereoisomer in ${ }_{65} 86 \%$ yield and $93 \%$ ee (Table 3, entry 2 ). Having established the optimal reaction protocol, a variety of substituted aromatic nitrostyrenes was investigated. Aromatic groups with electronrich and electron-deficient substituents were successfully utilized to form the bicyclic products in high yield and with excellent $e e$ 70 values (Table 3, entries 3-7). In addition, nitrostyrenes bearing heteroaromatic as well as other aromatic groups were also well tolerated (Table 3, entries 8,9 ). It should be noticed that a small percentage of the Michael adduct 6 was observed in all cases, lowering the yield of the desired product. All attempts to force 75 the second ring closing step on $\mathbf{6}$ by adding a base in the product mixture resulted in the epimerization of the $\alpha$-nitro carbon centre of 5 and subsequently retro-Henry degradation. The products were separated by FC chromatography.

The absolute configuration of the products was indicated by X80 ray crystallographic analysis ${ }^{14}$ of a crystal of compound 3a (Figure 1). On the basis of this result, a plausible mechanistic pathway is proposed to account for the stereochemical outcome of this reaction (see ESI $\dagger$ ).

In conclusion, we have developed an unprecedented 85 organocatalytic asymmetric addition of 1,4-cyclohexanedione to aromatic nitrodienes and nitrostyrenes, leading to complex 


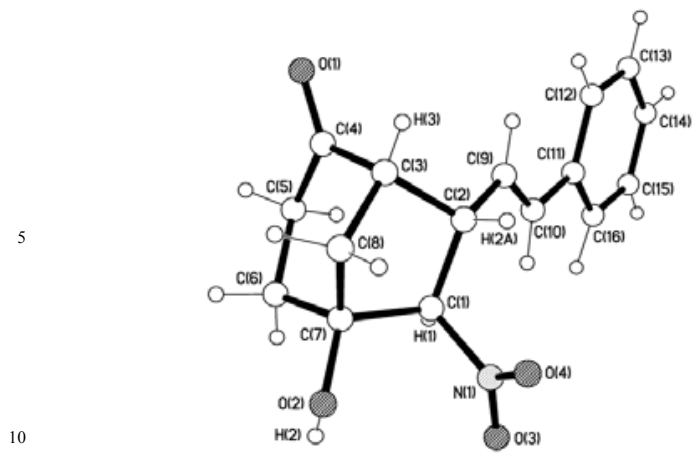

Fig. 1 X-Ray structure of enantiopure 3a.

bicyclo[3.2.1] octan-2-one derivatives containing four continuous stereogenic centres as a single diastereoisomer and with excellent 15 enantioselectivities. The products were delivered through a domino Michael-Henry process utilizing a proline-based bifunctional organocatalyst.

M. T. and C. G. K. acknowledge COST Action CM0905 (ORCA) and Prof. A. Malkov (Loughborough University) for 20 initiating the cooperation between the Universities of Athens and Loughborough. C. G. K. would like to acknowledge the Operational Program "Education and Lifelong Learning" for financial support through the NSRF program "METADIDAKTORES (PE 2431)" co-financed by ESF and the ${ }_{25}$ Greek State.

\section{Notes and references}

${ }^{a}$ Laboratory of Organic Chemistry, Department of Chemistry, University of Athens, Panepistimiopolis 15771, Athens, Greece. Fax: +30 210 7274761; Tel: +302107274281;E-mail: ckokotos@chem.uoa.gr $30{ }^{b}$ Loughborough University, Loughborough, LE11 3TU, UK. Fax: +44 1509 223925; Tel: +44 1509 228751;E-mail:m.r.j.elsegood@lboro.ac.uk $\dagger$ Electronic Supplementary Information (ESI) available: [Full optimization studies, proposed mechanism, characterization of the products, NMR, HPLC and crystallographic data]. See 35 DOI: $10.1039 / \mathrm{b} 000000 \mathrm{x} /$

1 For reviews on domino reactions, see: (a) K. C. Nicolaou, T. Montagnon and S. A. Snyder, Chem. Commun., 2003, 551; (b) J. C. Wasilke, S. J. Obrey, R. T. Baker and G. C. Bazan, Chem. Rev., 2005, 105, 1001; (c) J. Zhu and H. Bienayme, Multicomponent Reactions, Wiley-VCH, Weinheim, 2005; (d) L. F. Tietze, G. Brasche and K. Gericke, Domino Reactions in Organic Synthesis, Wiley-VCH, Weinheim, 2006; (e) H.-C. Guo and J.-A. Ma, Angew. Chem. Int. Ed., 2006, 45, 354; (f) K. C. Nicolaou, D. J. Edmonds and P. G. Bulger, Angew. Chem. Int. Ed., 2006, 45, 7134; (g) H. 45 Pellissier, Tetrahedron, 2006, 62, 2143; (h) C. J. Chapman and C. G. Frost, Synthesis, 2007, 1.

2 For books, see: (a) A. Berkessel and H. Groger, Asymmetric Organocatalysis- From Biomimetic Concepts to Powerful Methods for Asymmetric Synthesis, Wiley-VCH, Weinheim, 2005; (b) P. I.

50 Dalko, Enantioselective Organocatalysis Reactions and Experimental Procedure, Wiley-VCH, Weinheim, 2007.

3 For reviews on organocatalytic domino reactions, see: (a) D. Enders, C. Grondal and M. R. M. Huttl, Angew. Chem. Int. Ed. 2007, 46, 1570; (b) X. Yu and W. Wang, Org. Biomol. Chem., 2008, 6, 2037; (c) C. Grondal, M. Jeanty and D. Enders, Nat. Chem., 2010, 2, 167; (d) H. Pellissier, Adv. Synth. Catal., 2012, 354, 237.

4 For selected examples on organocatalyzed domino Michael- Henry reaction, see: (a) Y. Hayashi, T. Okano, S. Aratake and D. Hazelard, Angew. Chem. Int. Ed., 2007, 46, 4922; (b) D.-Q. Xu, Y.-F. Wang, 60 S.-P. Luo, S. Zhang, A.-G. Zhong, H. Chen and Z.-Y. Xu, Adv.
Synth. Catal., 2008, 350, 2610; (c) A. Adibekian, M. S. M. Timmer, P. Stallforth, J. Van Rijn, D. B. Werz and P. H. Seeberger, Chem. Commun., 2008, 3549; (d) R. Dodda, J. J. Goldman, T. Mandal, C.G. Zhao, G. Grant and E. R. T. Tiekink, Adv. Synth. Catal., 2008, 350, 537; (e) B. Tan, P. J. Chua, Y. Li and G. Zhong, Org. Lett., 2008, 10, 2437; (f) B. Tan, P. J. Chua, X. Zeng, M. Lu and G. Zhong, Org. Lett., 2008, 10, 3489; (g) J. L. Garcia Ruano, V. Marcos, J. A. Suanzes, L. Marzo and J. Aleman, Chem. Eur. J., 2009, 15, 6576; (h) H. Uehara, R. Imashiro, G. Hernandez- Torres and C. F. Barbas, Proc. Natl. Acad. Sci. U. S. A., 2010, 107, 20672.

5 For reviews on organocatalytic Michael reactions, see: (a) D. Almasi, D. A. Alonso and C. Najera, Tetrahedron: Asymmetry, 2007, 18, 299; (b) S. B. Tsogoeva, Eur. J. Org. Chem., 2007, 1701; (c) J. L. Vicario, D. Badia and L. Carillo, Synthesis, 2007, 2065; (d) D. Enders, C. Wang and J. X. Liebich, Chem. Eur. J., 2009, 15, 11058; (e) D. Roca-Lopez, D. Sadaba, I. Delso, R. P. Herrera, T. Tejero and P. Merino, Tetrahedron: Asymmetry, 2010, 21, 2561.

6 For reviews on organocatalytic Henry reactions, see: (a) C. Palomo, M. Oiarbide and A. Laso, Eur. J. Org. Chem., 2007, 2561; (b) S. 80 Gao, G. Xi, N. Li, C. Wang and J.-J. Ma, Chin. J. Org. Chem., 2010, 30, 1811; (c) Y. Alvarez- Casao, E. Marques- Lopez and R. P. Herrera, Symmetry, 2011, 3, 220.

7 (a) C. G. Kokotos and G. Kokotos, Adv. Synth. Catal., 2009, 351, 1355; (b) C. G. Kokotos, D. Limnios, D. Triggidou, M. Trifonidou and G. Kokotos, Org. Biomol. Chem., 2011, 9, 3386; (c) M. Tsakos, C. G. Kokotos and G. Kokotos, Adv. Synth. Catal., 2012, 354, 740; (d) M. Tsakos and C. G. Kokotos, Eur. J. Org. Chem., 2012, 576; (e) M. Tsakos, M. Trifonidou and C. G. Kokotos, Tetrahedron, 2012, 68, 8630 .

908 (a) D. Ding, C.-G. Zhao, Q. Guo and H. Arman, Tetrahedron, 2010, 66, 4423; (b) M. Rueping, A. Kuenkel and R. Fröhlich, Chem. Eur.J. 2010, 16, 4173 .

9 For a recent example of a transition-metal catalysed tandem MichaelHenry reaction between 1,2-cyclohexanedione and nitrostyrenes, see: W. Li, X. Liu, Z. Mao, Q. Chen and R. Wang, Org. Biomol. Chem., 2012, 10, 4767.

10 B. Tan, Y. Lu, X. Zeng, P. J. Chua and G. Zhong, Org. Lett., 2010, 12, 2682

11 For examples see: (a) K. Fujita, M. Node, M. Sai, E. Fujita, T. Shingu, W. H. Watson, D. A. Grossie and V. Zabel, Chem. Pharm. Bull., 1989, 37, 1465; (b) T. Kan, S. Hosokawa, S. Nara, M. Oikawa, S. Ito, F. Matsuda and H. Shirahama, J. Org. Chem., 1994, 59, 5532; (c) M. H. Filippini and J. Rodriguez, Chem. Rev., 1999, 99, 27; (d) L. Li, Z. Weng, S. Huang, J. Pu, S. Li, H. Huang, B. Yang, Y. Han, W. Xiao, M. Li, Q. Han and H. Sun, J. Nat. Prod., 2007, 70, 1295; (e) M. Torihata, T. Nakahata and S. Kuwahara, Org. Lett., 2007, 9, 2557; (f) R. M. Conrad and J. Du Bois, Org. Lett., 2007, 9, 5465; (g) K. C. Nicolaou, D. Pappo, K. Y. Tsang, R. Gibe and D. Y. Chen, Angew. Chem. Int. Ed., 2008, 47, 944; (h) K. C. Nicolaou, Q. Toh and D. Y. Chen, J. Am. Chem. Soc., 2008, 130, 11292; (i) J. Hayashida and V. H. Rawal, Angew. Chem. Int. Ed., 2008, 47, 4373; (j) M. Torihata and S. Kuwahara, Biosci. Biotechnol. Biochem., 2008, 72, 1628.

12 For selected reviews on enamine catalysis, see: (a) B. List, Tetrahedron, 2002, 58, 5573; (b) B. List, Acc. Chem. Res., 2004, 37, 548; (c) S. Mukherjee, J. W. Yang, S. Hoffman and B. List, Chem. Rev., 2007, 107, 5471; (d) P. M. Pihko, I. Majander and A. Erkkila, Top. Curr. Chem., 2010, 291, 29.

13 (a) N. Mase, F. Tanaka and C. F. Barbas III, Org. Lett., 2003, 5, 4369; (b) D. Gryko, M. Zimnicka and R. Lipinski, J. Org. Chem., 2007, 72, 964; (c) N. Zotova, A. Franzke, A. Armstrong and D. G. Blackmond, J. Am. Chem. Soc., 2007, 129, 15100; (d) J. Zhou, Q. Chang, L.- H. Gan and Y.-G. Peng, Org. Biomol. Chem., 2012, 10, 6732.

14. X-ray data for 3a. $\mathrm{C}_{16} \mathrm{H}_{17} \mathrm{NO}_{4}, M=278.30$, colourless block, $0.70 \times$ $0.21 \times 0.17 \mathrm{~mm}^{3}$, orthorhombic, $P 2_{1} 22_{1}, a=10.3329(10), b=$ 19.6202(19), $c=7.1804(7) \AA, V=1455.7(2) \AA^{3}, Z=4, \mu(\mathrm{Mo}-\mathrm{K} \alpha)=$ $0.10 \mathrm{~mm}^{-1}, T=150 \mathrm{~K}, 17114$ reflections measured on a Bruker APEX $2 \mathrm{CCD}$ diffractometer, 4410 unique, $R_{\text {int }}=0.033, R_{1}\left[F^{2}>2 \sigma\left(F^{2}\right)\right]=$ $0.041, w R_{2}$ (all data) $=0.107$, Flack $\mathrm{x}=-0.6(4)$; not reliably determined, but gives an indication. $\mathrm{H}$ atoms freely refined. CCDC 916313 contains the supplementary crystallographic data for this 
paper. These data can be obtained free of charge from The

Cambridge Crystallographic Data Centre via

www.ccdc.cam.ac.uk/data_request/cif. 